\title{
PROSES PERENCANAAN KEPERAWATAN DAN PROSES DALAM IMPLEMENTASI
}

\section{NADIA FEBRIANI BR. BARUS}

\author{
Nadiafebriani001@gmail.com
}

Latar belakang: Keperawatan di Indonesia saat ini masih dalam suatu proses profesionalisasi yaitu terjadinya suatu perubahan dan perkembangan karakteristik sesuai tuntutan secara global dan lokal / otonomi. Untuk mewujudkannya maka perawat Indonesia harus mampu memberikan asuhan keperawatan secara profesional kepada klien dan berpartisipasi aktif dalam pembangunan bangsa dan negara. Keperawatan adalah ilmu dan kiat yang berkenaan dengan masalahmasalah fisik, psikologi, sosiologis, budaya dan spiritual dari individu. Ilmu keperawatan didasarkan atas kerangka teori yang luas, kiatnya tergantung pada ketrampilan merawat dan kemampuan perawat secara individual. Pentingnya perawat dalam sistem perawatan kesehatan telah dikenal dalam banyak hal yang positip, dan profesi keperawatan itu sendiri sedang menyatakan kebutuhan untuk para praktisinya agar menjadi profesional dan bertanggung jawab. Pelayanan keperawatan dilakukan dalam upaya meningkatkan derajat kesehatan, mencegah penyakit, penyembuhan, pemulihan serta pemeliharaan kesehatan dengan penekanan pada upaya pelayanan kesehatan utama untuk memungkinkan setiap penduduk mencapai kemampuan hidup sehat dan produktif. Ilmu Keperawatan didasarkan pada suatu teori yang sangat luas. Proses keperawatan adalah metode dimana suatu konsep diterapkan dalam praktik keperawatan. Hal ini bisa disebut sebagai suatu pendekatan problemsolving yang memerlukan ilmu, teknik, dan ketrampilan interpersonal dan ditujukan untuk memenuhi kebutuhan klien/ keluarga. Proses keperawatan terdiri dari lima tahap yang sequensial dan berhubungan. Antara lain yaitu pengkajian, diagnosis, perencanaan, pelaksanaan, dan evaluasi. Tahap tersebut berintegrasi dalam mendefinisikan suatu tindakan perawatan. Salah satunya adalah implementasi atau pelaksanaan. Proses keperawatan menyediakan struktur bagian praktis dengan penggunaan pengetahuan dan keterampilan yang dilakukan oleh perawat untuk mengekspresikan kebutuhan perawatan (human caring). Keperawatan digunakan secara terus-menerus ketika merencanakan dan memberikan asuhan keperawatan dengan mempertimbangkan pasien sebagai figur central dalam merencanakan asuhan dengan mengobservasi respons pasien terhadap setiap tindakan sebagai penatalaksanaan dalam suatu asuhan keperawatan. Pada saat implementasi perawat harus melaksanakan hasil dari rencana keperawatan yang di lihat dari diagnosa keperawatan. Di mana perawat membantu klien dari masalah status kesehatan yang dihadapi kestatus kesehatan yang lebih baik yang menggambarkan kriteria hasil yang diharapkan. Sehingga, dengan proses keperawatan, rasa tanggung jawab dan tanggung gugat bagi perawat itu dapat dimiliki dan dapat digunakan dalam tindakan-tindakan yang merugikan atau menghindari tindakan yang 
legal. Semua tatanan perawatan kesehatan secara hukum perlu mencatat observasi keperawatan, perawatan yang diberikan, dan respons pasien.

Metode: Proses keperawatan merupakan metode ilmiah yang dipakai dalam memberikan asuhan keperawatan yang profesional. Perawat, dimana saja ia bertugas, menghadapi klien dengan segala macam kasus, dan melayani klien pada semua tingkat usia juga harus menggunakan proses keperawatan. Perawat diharapkan memahami tentang konsep proses keperawatan dan mampu menerapkan serta menyusunannya dalam sebuah dokumen status kesehatan klien Asuhan profesional dituntut untuk dapat melaksanakan proses keperawatan dengan tepat dan benar. Pemahaman mahasiswa terhadap proses perawatan sangat penting, karena topik ini akan menjadi bagian yang amat penting dalam pelaksanaan asuhan keperawatan. Perbedaan asuhan yang profesional dengan asuhan tradisional terletak pada penggunaan proses keperawatan. Kemampuan perawat dalam menerapkan proses keperawatan dalam asuhannya sudah tidak dapat ditawar lagi apabila ia meyakini bahwa asuhannya adalah asuhan yang profesional. Oleh karena itu diperlukan suatu metode pembelajaran klinik yang dapat membantu meminimalkan hambatan yang ada dan dapat mencapai tujuan belajar seccara optimal yaitu penerapan asuhan keperawatan dengan pendekatan proses keperawatan. Kemampuan para pendidik klinik keperawatan dalam membantu para praktikan menerapkan konsep proses keperawatan dalam asuhan yang nyata sangat diperlukan. Pendidik klinik yang handal dapat mengeksplorasi kemampuan mahasiswa secara optimal.

Hasil: Hasil penelitian ditemukan ada empat tematerkait sustainability implementasi asuhan keperawatan isolasi sosial yaitu

1) perubahanperilaku klien,2) peningkatan pengetahuan keluarga dalam merawat anggota keluarga dengan isolasi sosial, 3) meningkatkan keterampilan perawat dalam merawat klien,dan4) meningkatkan kinerja perawat.

\section{Perubahan perilaku klien}

Asuhan keperawatan isolasi sosial yang diberikan kepada klien secara langsung dapat memberikan pengaruh terhadap diri dan perilaku klien. Perilaku menarik diri pada klien merupakan respon yang muncul dari penilaian klien terhadap stressor yang dialami. Asuhan keperawatan isolasi social yang diberikan perawat dapat membantu perawat untuk melihat perkembangan dari klien sendiri. Pengalaman perawat selama merawat klien isolasi sosial menimbulkan persepsi yang beragam terhadap manfaat yang dirasakan baik untuk perawat dan klien, diantaranya klien dapat mengenali dirinya dan terjadi perubahan pada perilaku klien. Klien dapat mengenali dirinya Dua partisipan mengungkapkan ketika memberikan asuhan keperawatan kepada klien isolasi sosial, mereka menemukan bahwa ada perkembangan pada 
klien dalam mengenali diri dan masalahnya sebagaimana disampaikan sebagai berikut : "pasien juga dapat mengenali perawat, trus pasien dapat menyebutkan namanya siapa" (P1) "pasien yang tidak tau menjadi tau apa penyebab dia masuk ke rumah sakit kita" (P2) Perubahan perilaku klien Semua partisipan mengungkapkan bahwa setelah diberikan asuhan keperawatan isolasi sosial terjadi perubahan perilaku pada klien, seperti yang disampaikan oleh tiga partisipan berikut : "dari yang gelisah menjadi tidak gelisah, eee...pasien jadi cepat berkurang gejalanya, pasien yang isos jadi aktif" (P2) "mau ngomong walupun dikit-dikit, mau baur, mau ikut-ikut kegiatan ruangan.. itulah dak perubahan-perubahannyo" (P3) "setelah lima hari dirawat dia kalo kakak ajak interaksi pasti dia mau eee... natap wajah kakak" (P7) 2. Meningkatkan kemampuan kelua

rga dalam merawat klien Asuhan keperawatan isolasi sosial terdiri dari asuhan keperawatan untuk klien dan asuhan keperawatan untuk keluarga. Tujuan dari pemberian asuhan keperawatan kepada keluarga adalah untuk meningkatkan kemampuan keluarga dalam merawat klien dirumah dan menjadi sistem pendukung yang efektif untuk klien. Pengalaman perawat selama memberikan asuhan keperawatan isolasi sosial kepada keluarga menimbulkan persepsi yang beragam terhadap keterlibatan keluarga dalam merawat klien, diantaranya keterbatasan keluarga dalam merawat klien, meningkatkan kemampuan keluarga dalam merawat klien, dan respon positif keluarga dan masyarakat

PEMBAHASAN: Implementasi keperawatan adalah serangkaian kegiatan yang dilakukan oleh perawat untuk membantu klien dari masalah status kesehatan yang dihadapi kestatus kesehatan yang lebih baik yang menggambarkan kriteria hasil yang diharapkan (Gordon, 1994, dalam Potter \& Perry, 1997). Implementasi merupakan inisiatif dari rencana tindakan untuk mencapai tujuan yang spesifik. Tahap pelaksanaan dimulai setelah rencana tindakan disusun dan ditujukan pada nursing orders untuk membantu klien mencapai tujuan yang diharapkan. Oleh karena itu rencana tindakan yang spesifik dilaksanakan untuk memodifikasi faktor-faktor yang mempengaruhi masalah kesehatan klien. Tujuan dari pelaksanaan adalah membantu klien dalam mencapai tujuan yang telah ditetapkan, yang mencakup peningkatan kesehatan, pencegahan, penyakit, pemulihan kesehatan dan memfasilitasi koping.

Untuk kesuksesan pelaksanaan implementasi keperawatan agar sesuai dengan rencana keperawatan, perawat harus mempunyai kemampuan kognitif (intelektual), kemampuan dalam hubungan interpersonal, dan keterampilan dalam melakukan tindakan. Proses pelaksanaan implementasi harus berpusat kepada kebutuhan klien, faktor-faktor lain yang mempengaruhi kebutuhan keperawatan, strategi implementasi keperawatan, dan kegiatan komunikasi. (Kozier 
et al., 1995). Menggunakan metode pemecahan masalah Pendekatan proses keperawatan memungkinkan perawat untuk mengidentifikasi seluruh kebutuhan yang diperlukan klien. Kebutuhan ini menggambarkan masalah yang terjadi pada klien baik aKtual maupun risiko. Identifikasi masalah keperawatan yang ada merupakan dasar bagi perawat untuk menetapkan desain pemecahan masalahnya. Sehingga tindakan yang dilakukan terhadap klien merupakan tindakan yang bertujuan untuk memecahkan masalah yang terjadi pada klien. Proses keperawatan adalah serangkaian tindakan yang sistematis berkesinambungan meliputi tindakan untuk mengidentifikasi masalah kesehatan individu atau kelompok baik yang aktual maupun potensial kemudian merencanakan tindakan untuk menyelesaikan, mengurangi, atau mencegah terjadinya masalah baru dan melaksanakan tindakan atau menugaskan orang lain untuk melaksanakan tindakan keperawatan serta mengevaluasi keberhasilan dari tindakan yang dikerjakan. Proses keperawatan adalah aktivitas yang mempunyai maksud yaitu praktik keperawatan yang dilakukan dengan cara yang sistematik. Selama melaksanakan proses keperawatan, perawat menggunakan dasar pengetahuan yang komprehensif untuk mengkaji status kesehatan klien, membuat penilaian yang bijaksana dan mendiagnosa, mengidentifikasi hasil akhir kesehatan klien dan merencanakan, menerapkan dan mengevaluasi tindakan keperawatan yang tepat guna mencapai hasil akhir tersebut. Proses keperawatan adalah salah satu metoda efektif pemecahan masalah yang dilakukan perawat terhadap klien dengan pendekatan metodologi ilmiah. Asuhan keperawatan dapat dipertanggungjawabkan berdasarkan substansi ilmiah yaitu logis, sistimatis, dinamis dan terstruktur Proses keperawatan adalah suatu metode ilmiah yang sistematis dan terorganisir dalam memberikan asuhan keperawatan pada pasien yang berfokus pada respon individu terhadap gangguan kesehatan yang dialami. Peningkatan pengetahuan keluarga dalam merawat klien isolasi social Manfaat lain yang dapat dirasakan dari implementasi asuhan keperawatan isolasi sosial adalah pada keluarga klien. Implementasi standar asuhan keperawatan diberikan tidak hanya kepada klien yang dirawat di pelayanan kesehatan saja, namun juga diberikan kepada keluarga klien, yang bertujuan agar keluarga dapat merawat klien dirumah dan menjadi sistem pendukung yang efektif untuk klien. Menurut Freidman, Bowden, dan Jones(2010) terdapat lima fungsi dasar keluarga yaitu fungsi afektif, fungsi sosialisasi, fungsi reproduksi, fungsi ekonomi, dan fungsi perawatan keluarga. Fungsi perawatan keluarga adalah fungsi dimana keluarga berfungsi dalam merawat anggota keluarga yang sakit. Namun pada beberapa keadaan, masih ada keluarga klien yang merasa tidak mampu untuk melaksanakan fungsi perawatan keseatan karena banyak factor antara lain karena ekonomi dan psikologis dari keluarga yang tidak siap menerima keadaan klien. kemampuan untuk berkomunikasi dan menyampaikan informasi, dan 3)kemampuan teknikal, yaitu kemampuan untuk melaksanakan prosedur, metode dan menggunakan peralatan, hasil wawancara menujukkan bahwa kemampuan teknikal perawat untuk merawat klien isolasi sosial semakin meningkat. Kondisi klien isolasi sosial telah meningkatkan kesadaran diri perawat untuk menumbuhkan tanggung jawab diri dalam 
membantu menyelesaikan masalah klien. Hal ini sesuai dengan tujuan profesi dan praktik keperawatan yang memiliki tanggung jawab secara mandiri. Tanggung jawab merupakan kemampuan perawat untuk melaksanakan tugas pekerjaannya dengan mematuhi ketentuan tanpa diawasi terus menerus (Kron\& Gray, 1987). Perawat telah memiliki kewenangan, otonomi, dan tanggung jawab secara mandiri untuk memberikan pelayanan keperawatan. Tugas-tugas dan keadaan klien isolasi sosial telah menumbuhkan kesadaran diri perawat untuk terus memberikan perhatian dan menunjukkan kepedulian kepada klien isolasi sosial. Implementasi rencana strategis Prosedur dan langkah-langkah implementasi rencana strategis pelayanan keperawatan di Rumah Sakit Bunga Kota Citra ini terdiri dari 4 tahapan yang meliputi pertama menjelaskan rencana strategis apa yang akan dilakukan; kedua menjelaskan kepada siapa rencana strategis ini ditunjukan; ketiga membuat prosedur tentang rencana strategis tersebut; keempat disusunlah anggaran sesuai program yang akan dijalankan tersebut. Merupakan suatu proses penyusunan berbagai intervensi keperawatan yang dibutuhkan untuk mencegah, menurunkan, atau mengurangi masalah-masalah klien. Perencanaan ini merupakan langkah ketiga dalam membuat suatu proses keperawatan. Perencanaan adalah merupakan bagian dari fase pengorganisasian dalam proses keperawatan sebagai pedoman untuk mengarahkan tindakan keperawatan dalam usaha membantu, meringankan, memecahkan masalah atau untuk memenuhi kebutuhan klien.Suatu perencanaan yang tertulis dengan baik akan memberi petunjuk dan arti pada asuhan keperawatan karena perencanaan adalah sumber informasi bagi semua yang terlibat dalam asuhan keperawatan klien.

Perencanaan merupakan suatu petunjuk tertulis yang menggambarkan secara tepat rencana tindakan keperawatan yang dilakukan terhadap klien sesuai dengan kebutuhannya berdasarkan diagnosis keperawatan. Tujuan dari rencana perawatan adalah memberikan tindakan perawatan berdasarkan respon klien terhadap masalah kesehatannya, dan mencegah masalah baru yang akan timbul. Perencanaan dan tindakan keperawatan adalah tahap dalam proses keperwatan berdasarkan masalah aktual dari klien.

Tujuan intervensi adalah sebagai pengantar untuk mengatur atau mendesain tindakan perawatan berdasarkan respon klien terhadap masalah kesehatannya, dengan sasaran mencegah, menghilangkan atau meminimalkan penyebab yang mempengaruhi status kesehatan tersebut.

Tujuan dokumentasi tahap perencanaan:

- Sebagai kerangka kerja dalam implementasi keperawatan

- Merupakan inti dokumentasi keperawatan yang berorientasi pada masalah

- Sebagai referensi dalam melkukan modifikasi rencana keperawatan 
- Sarana komunikasi tim keperawatan dalam pendelegasian tugas/instruksi keperawatan

- Sebagai landasan ilmiahyang logis dan sistimatis dalam mengerjakan asuhan keperawatan kepada pasien.

- $\quad$ Agar semua rencan tindakan dapat dipilih disesuaikan kondisi klien sehingga efektif.

Penerapan proses keperawatan dalam asuhan keperawatan untuk klien merupakan salah satu wujud tanggung jawab dan tanggung gugat perawat terhadap klien. Pada akhirnya, penerapan proses keperawatan ini akan meningkatkan kualitas layanan keperawatan kepada klien.

Proses keperawatan merupakan cara yang sistematis yang dilakukan oleh perawat bersama dengan klien dalam menentukan asuhan keperawatan dengan melakukan pengkajian, merumuskan diagnose, merencanakan tindakan yang akan dilakukan, melaksanakan tindakan serta mengevaluasi hasil asuhan yang telah diberikan dengan berfokus pada klien. Lalu kelima proses tersebut didokumentasikan oleh perawat pada sebuah catatan keperawatan.

\section{Penutup:}

Implementasi merupakan inisiatif dari rencana tindakan untuk mencapai tujuan yang spesifik. Tahap pelaksanaan dimulai setelah rencana tindakan disusun dan ditujukan pada nursing orders untuk membantu klien mencapai tujuan yang diharapkan. Pelaksanaan tindakan keperawatan harus diikuti oleh pencatatan yang lengkap dan akurat terhadap suatu kejadian dalam proses keperawatan. Seluruh perawat agar meningkatkan pemahamannya terhadap berbagai cara pendokumentasian implementasi keperawatan sehingga dapat dikembangkan dalam tatanan layanan keperawatan. Diharapkan agar perawat bisa menindak lanjuti pendokumentasian tersebut melalui kegiatan asuhan keperawatan sebagai dasar untuk pengembangan kedisiplinan di Lingkungan Rumah Sakit dalam ruang lingkup keperawatan. Proses keperawatan merupakan suatu kegiatan yang terorganisir dengan menggunakan metode yang sistematis dalam memberikan Auhan Keperawatan kepada individu,kelompok,keluarga dan masyarakat terhadap masalah kesehatan yang dialami.Proses keperawatan terdiri dari 5 tahap yaitu: Pengkajian, Diognasa, Perencanaan, Pelaksanaan dan Evaluasi. Tahap-tahap dalam proses keperawatan saling berkesinambungan dan tidak dapat di pisahkan satu sama lain. 


\section{Daftar pustaka:}

1. Butar-Butar, J., \& Simamora, R. H. (2016). Hubungan Mutu Pelayanan Keperawatan dengan Tingkat Kepuasan Pasien Rawat Inap di RSUD Pandan Kabupaten Tapanuli Tengah. Jurnal Ners Indonesia, 6(1), 50-63.

2. Simamora, R. H. (2005). Hubungan Persepsi Perawat Pelaksana Terhadap Penerapan Fungsi Pengorganisasian Yang Dilakukan Oleh Kepala Ruangan Dengan Kinerjanya Diruang Rawat Inap RSUD Koja Jakarta Utara (Doctoral dissertation, Tesis FIK UI, Tidak dipublikasikan).

3. Retty Octi Syafrini, Budi Anna Keliat \& Yossie Susanti Eka Putri.2020. PERSEPSI PERAWAT PELAKSANA TERHADAP IMPLEMENTASI ASUHAN KEPERAWATAN ISOLASI SOSIAL DALAM PROGRAM MPKP JIWA. Jurnal IImu Keperawatan Jiwa. Volume 3. No 2, Hal 209 - 220.

4. Wiwin Sulistyawati.2016. HUBUNGAN IMPLEMENTASI ASESMEN KOMPETENSI DENGAN PELAKSANAAN DISCHARGE PLANNING. Jurnal Care Vol. 4, No.3,.hal 124-131.

5. Meylona Verawaty Zendrato \& Rr. Tutik Sri Hariyati.2017. OPTIMALISASI PENGELOLAAN ASUHAN KEPERAWATAN DI INSTALASI RAWAT JALAN RUMAH SAKIT X. JPPNI Vol.02.No.02.hal 86-99

6. Samsualam,Rahmat Hidaya \& KKaryanti Lestari.2018.Studi Eksplorasi Religiusitas dan Implementasi Asuhan Keperawatan Spiritual Muslim PSIK FKM UMI 2018. Jurnal Kesehatan, Vol. 1 No. 4.HAL 347-354

7. Nikmatur Rohmah.2012.INTEGRASI PROSES KEPERAWATAN DALAM PEMBELAJARAN KLINIK KEPERAWATAN ONE TO ONE TEACHING AND FEED BACK. THE INDONESIAN JOURNAL OF HEALTH SCIENCE, Vol. 1, No. 1.hal 51-60

8. M. Saubari Azhar N., Wahyudin, Machli Riyadi.2018.IMPLEMENTASI RENCANA STRATEGIS PELAYANAN KEPERAWATAN DALAM PERSPEKTIF KEPEMIMPINAN KEPALA RUANGAN BERBASIS BUDAYA ORGANISASI DI RUMAH SWASTA (Implementation Of Strategic Planning For Nursing Services In The Leadership Perspective Of The Head Of Room Based On Organizational Culture In Private General Hospital). journal.umbjm.ac.id/index.php/caring-nursing. Vol. 2 No. 2.hal 51-59 
9. Ana Pratiwi, Aziz Alimul Hidayat \& Ratna Agustin.2016. IMPLEMENTASI SISTEM MANAJEMEN MUTU PELAYANAN KEPERAWATAN MELALUI KEPEMIMPINAN MUTU KEPALA RUANGAN (Implementation of Quality Management System of Nursing Care Through Quality Leadership of Nurse Unit Manager). Jurnal Ners Vol. 11 No.1. Hal 1-6.

10. Rosari Tarigan \& Hanny Handiyani.2019. Manfaat Implementasi Dokumentasi Asuhan Keperawatan Berbasis Komputerisasi Dalam Meningkatkan Mutu Asuhan Keperawatan. Jurnal IImiah Kesehatan Pencerah,vol 08.no (2), Hal 110-116.

11. Hasrul \& Rini Muin.2017. HUBUNGAN TINGKAT PENGETAHUAN PERAWAT TERHADAP PELAKSANAAN ASUHAN KEPERAWATAN SPIRITUAL DI RUANG PERAWATAN RUMAH SAKIT NENE MALLOMO KABUPATEN SIDENRENG RAPPANG TAHUN 2017. Jurnal Keperawatan Muhammadiyah. Vol.2. no 1. Hal 11-17

12. Ratna Agustin.2017. OPTIMALISASI PELAKSANAAN DISCHARGE PLANNING MELALUI PENGEMBANGAN MODEL DISCHARGE PLANNING TERINTEGRASI PELAYANAN KEPERAWATAN. Jurnal Keperawatan Muhammadiyah. Vol 2.no 1. Hal 98107 